Available online at GSC Online Press Directory

GSC Advanced Research and Reviews e-ISSN: 2582-4597, CODEN (USA): GARRC2

Journal homepage: https://www.gsconlinepress.com/journals/gscarr

(RESEARCH ARTICLE)

\title{
Phytochemical and antimicrobial screening of sitopaladi churna
}

\author{
Ekbote Maruthi T $1{ }^{1}{ }^{*}$, Rajashekar KV ${ }^{2}$, Shankarappa $\mathrm{L}^{1}$ and Bharathi DR ${ }^{3}$ \\ ${ }^{1}$ Department of Pharmacognosy, S.J.M. College of Pharmacy, Chitradurga-577502. Karnataka, India. \\ 2 Departmentof Dravyagunavignana, Sri Raghavendra Ayurveda Medical College and Hospital, Malladihalli-577531. \\ ${ }^{3}$ Department of pharmacology, S.J.M. College of Pharmacy, Chitradurga-577502. Karnataka, India.
}

Publication history: Received on 07 December 2019; revised on 19 December 2019; accepted on 22 December 2019

Article DOI: https://doi.org/10.30574/gscarr.2019.1.2.0011

\begin{abstract}
Ayurvedic medicines are being used increasingly to fight or prevent common diseases. Sitopaladi churna is a polyherbal formulation containing Piper longum (Piperceae), Elettaria cardamom (Zingiberaceae), Cinnamomum zeylanicum (Lauraceae). Methanolic and Aqueous extracts of Sitopaladi Churna was screened for their antimicrobial activity against Bacillus subtilis, Staphylococcus aureus, Escherichia coli, Pseudomonas aeruginosa, Aspergillus niger and Candida albicans. The results of antimicrobial activity of Aqueous and Methanolic extracts of the Sitopaladi churna indicated that methanolic extract inhibited the growth of one or more test pathogens than aqueous extract. Sitopaladi churna formulation extracts showed a broad spectrum of antimicrobial activity. Phytochemical investigation revealed the presence of tannins, saponins, alkaloids, glycosides, flavonoids and triterpinoids. This may be due to the multifunctional effect of all the three plant ingredients of Sitopaladi churna.
\end{abstract}

Keywords: Sitopaladi Churna; Antimicrobial; Phytochemical

\section{Introduction}

Infectious diseases account for approximately one-half of all deaths in tropical countries. Incidents of epidemics due to drug resistant microorganisms and the emergence of hitherto unknown disease-causing microbes, pose enormous public health concerns. Natural products, either as pure compounds or as standardized plant extracts, provide unlimited opportunities for new drug leads because of the unmatched availability of chemical diversity. The increasing failure of chemotherapeutics and antibiotic resistance exhibited by pathogenic microbial infectious agents has led to the screening of formulations used in alternative system of medicine for their potential antimicrobial activity [1].

Sitopaladichurna is a polyherbal formulation containing Piper longum (Piperceae), Elettaria cardamom (Zingiberaceae) and Cinnamomum zeylanicum (Lauraceae) which have been prescribed for fever and gastric disorder [2]. Piper longum (Fruit) Hipli the fruit contains a large number of alkaloids and related compounds, the most abundant of which is piperine [3-4]. Elettaria cardamom (Seeds) Elachi, major phytochemical metabolites such as alpha pinene (1.5\%), betapinene $(0.2 \%)$, and other components have been identified [5]. Cinnamomum zeylanicum (Lauraceae) contains cinnamaldehyde do possess antibacterial and antifungal activity [6]. Sitopaladi churna serve as a useful formulation in reliving gastric disorders therefore the present study objective is to evaluate for antimicrobial effect of the formulation.

\section{Experimental methods}

The Sitopaladi churna is an ayurvedic proprietary medicine procured from Ayurvedic Pharmacy of Raghvendra Ayurvedic Medical College Malladihalli Holiakere Tq Chitradurga.

\footnotetext{
${ }^{*}$ Corresponding author

E-mail address: mekbote2015@yahoo.co.in
} 


\subsection{Preparation of extracts}

The collected churna formulation $25 \mathrm{~g}$ was extracted with $200 \mathrm{ml}$ of chloroform water macerated for 7 days filtered and evaporated on water bath at low temperature not exceeding $60^{\circ} \mathrm{C}$ and methanolic extract was also prepared similarly. Both the extracts were distilled, dried and used for the phytochemical [7-8] and antimicrobial study [9-10].

\subsection{Phytochemical screening of crude extracts}

Phytochemical tests were carried out to find out the presence of phytoconstituents viz., alkaloids, glycosides, flavonoids, tannins, triterpenoids saponins etc., and the results are shown in Table 1.

Table 1 Phytochemical screening of aqueous and methanolic extracts of Sitopaladi churna

\begin{tabular}{lcc}
\hline Test & Aqueous Extract & Methanolic Extract \\
\hline Alkaloids & - & + \\
Carbohydrates & + & + \\
Flavonoids & + & + \\
Triterpenoids & - & + \\
Resins & - & - \\
Saponins & + & + \\
Steroids & - & + \\
Tannins & + & + \\
\hline
\end{tabular}

\subsection{Antibacterial activity using cup plate method}

Bacillus subtilis (NCIM 2920), Klebsiella pneumoniae (NCIM 2883), Staphylococcus aureus (NCIM 5022), Escherichia coli (NCIM 2065), Pseudomonas aeruginosa (NCIM 2945), Aspergillus niger (NCIM 798), and Candida albicans (NCIM 3103 ). These cultures were procured from National Collection of Industrial Microorganism (NCIM), Pune, India.

\subsubsection{Antibacterial activity}

The extracts and the standard drugs were dissolved in minimum quantity of DMSO and adjusted, to make up the volume with sterile distilled water to get 100 and $200 \mu \mathrm{g} / \mathrm{ml}$ concentrations. The benzyl penicillin $(50 \mu \mathrm{g} / \mathrm{ml})$ was used against Gram positive and streptomycin was used against Gram negative bacteria as standard drugs. The antibacterial activity tests were performed by cup plate method. The fresh cultures of bacteria, Bacillus subtilis, Staphylococcus aureus, Escherichia coli and Pseudomonas aeruginosa were cultivated by inoculating into peptone broth and incubated at $37 \pm 2$ ${ }^{\circ} \mathrm{C}$ for 18-24 hours. This culture was mixed with Mueller Hinton agar media and poured into Petri dishes by following aseptic techniques. After solidification of the media, six bores were made at equal distance by using sterile steel cork borer ( $8 \mathrm{~mm}$ diameter). Into these cups different concentrations of test extracts and standard drugs were introduced. DMSO was used as a control. After introduction of standard drugs and the extracts to be screened, the plates were placed in a refrigerator at 8-10 ${ }^{\circ} \mathrm{C}$ for proper diffusion of drugs into the media. After two hours of cold incubation, the petriplates were maintained in an incubator at $37{ }^{\circ} \mathrm{C}$ for $24 \mathrm{hrs}$. The plates were observed for clear zone formation around the well and the experiment was carried out in triplicate. Antibacterial activities were expressed in millimeter Table 2.

Table 2 Antibacterial activity of aqueous and methanolic extracts of Sitopaladi churna

\begin{tabular}{|c|c|c|c|c|c|c|c|}
\hline \multirow{3}{*}{ Sl. No } & \multirow{3}{*}{ Organism } & \multicolumn{6}{|c|}{ Mean zone of inhibition (in $\mathrm{mm}$ ) } \\
\hline & & \multirow{2}{*}{$\begin{array}{c}\begin{array}{c}\text { Streptomycin } \\
\mu \mathrm{g} / \mathrm{ml}\end{array} \\
50\end{array}$} & \multirow{2}{*}{$\begin{array}{c}\begin{array}{c}\text { Benzyl Penicillin } \\
\boldsymbol{\mu} \mathrm{g} / \mathrm{ml}\end{array} \\
50\end{array}$} & \multicolumn{2}{|c|}{$\begin{array}{c}\text { Aqueous } \\
\mu \mathrm{g} / \mathrm{ml}\end{array}$} & \multicolumn{2}{|c|}{$\begin{array}{c}\text { Methanolic } \\
\mu \mathrm{g} / \mathrm{ml}\end{array}$} \\
\hline & & & & 100 & 200 & 100 & 200 \\
\hline 1 & Bacillus subtilis & -- & 18 & 11 & 13 & 13 & 15 \\
\hline 2 & Staphylococcus aureus & -- & 20 & 12 & 13 & 13 & 16 \\
\hline 3 & Pseudomonas aeruginosa & 19 & -- & 09 & 12 & 15 & 16 \\
\hline 4 & Escherichia coli & 21 & -- & 10 & 13 & 14 & 17 \\
\hline
\end{tabular}




\subsubsection{Anti-fungal activity}

The antifungal activity was studied by cup plate method as described above. The 24 hours fungus cultures of Candida albicans (NCIM 3103) and Aspergillus niger (NCIM 798) were inoculated into Potato-Dextrose agar media and transfered into petriplates. After solidification six bores $(8 \mathrm{~mm})$ were made with the help of sterile cork borer. Standard drug Griseofulvin $(50 \mu \mathrm{g} / \mathrm{ml})$ and extract solutions $(100 \mu \mathrm{g} / \mathrm{ml}$ and $200 \mu \mathrm{g} / \mathrm{ml})$ were prepared in DMSO separately and introduced into the wells. Only DMSO was introduced into a well, which served as control. The test plates were incubated at $25^{\circ} \mathrm{C}$ for $24 \mathrm{hrs}$ and zone of inhibition were measured, and the results were tabulated in Table 3.

Table 3 Antifungal activity of aqueous and methanolic extracts of Sitopaladi churna

\begin{tabular}{llccccc}
\hline & & \multicolumn{3}{c}{ Mean zone of inhibition (in mm) } \\
\cline { 3 - 7 } S1. No & Organism & $\begin{array}{c}\text { Griseofulvin } \\
\boldsymbol{\mu g} / \mathbf{m l}\end{array}$ & $\begin{array}{c}\text { Aqueous } \\
\mathbf{\mu g} / \mathbf{m l}\end{array}$ & $\begin{array}{c}\text { Methanolic } \\
\boldsymbol{\mu g} / \mathbf{m l}\end{array}$ \\
\cline { 3 - 7 } & & 50 & 100 & 200 & 100 & 200 \\
& & 18 & 10 & 11 & 12 & 13 \\
2 & Candida albicans & 19 & 11 & 12 & 12 & 14 \\
\hline
\end{tabular}

\section{Results and discussion}

\subsection{The phytochemical screening}

Of the aqueous extract showed the presence of Carbohydrates, Flavonoids, Saponins, and Tannins. Methanolic extract showed the presence of Alkaloids, Carbohydrates, Flavonoids, Triterpinoids, Saponins, Steroids and Tannins.

\subsection{Antibacterial activity}

Both the aqueous and methanolic extracts of the formulation possessed antibacterial activity in a concentration dependent manner against the test organisms at concentrations of 100 and $200 \mu \mathrm{g} / \mathrm{ml}$ and are comparable with the standard drug benzyl penicillin and streptomycin. The result of the extract was however found to be less than the reference drugs at concentrations studied. The results of the aqueous and methanolic extracts of the formulation were subjected to antibacterial activity revealed both extracts showed encouraging results and are tabulated in (Table 2). Both the aqueous and methanolic extracts of the formulation possessed antibacterial activity in a concentration dependent manner against the test organisms at concentrations of 100 and $200 \mu \mathrm{g} / \mathrm{ml}$ and are comparable with the standard drug Streptomycin and benzyl penicillin. The result of the extract was however found to be lesser than the reference drugs at concentrations studied. In the methanolic extracts, maximum zone of inhibition was recorded by $E$. coli at both the concentrations ( 14 and $17 \mathrm{~mm}$ ) while Pseudomonas aeruginosa recorded minimum zone of inhibition $(12$ and $15 \mathrm{~mm})$ at similar concentrations indicating gram negative organisms susceptibility. In aqueous extract, E. coli was found to be more sensitive (10 and $13 \mathrm{~mm}$ ) followed by Pseudomonas aeruginosa (09 and $12 \mathrm{~mm})$. With regard to gram positive bacteria in aqueous extract results is Bacillus subtilis (11 and $13 \mathrm{~mm}$ ) and Staphylococcus aureus (12 and $13 \mathrm{~mm}$ ). Similarly with Methanolic extract results is Bacillus subtilis (13 and $15 \mathrm{~mm}$ ) and Staphylococcus aureus (13 and $16 \mathrm{~mm}$ ). Further, among the two extracts studied, both gram positive and gram negative organisms are susceptible whereas methanolic extract was found to be more effective in terms of antibacterial activity.

\subsection{Antifungal activity}

In antifungal studies among the both extracts experimented, methanolic extract has shown zone of inhibition in a dose dependent manner (Table 3). Candida albicans exhibited 12 and $13 \mathrm{~mm}$. of inhibition at 100 and $200 \mu \mathrm{g} / \mathrm{ml}$ concentration respectively, while Aspergillus niger has shown 12 and $14 \mathrm{~mm}$ of clear zone at similar concentrations thus indicating sensitivity. However the zone of inhibition was less when compared to the reference drug griseofulvin.

\section{Conclusion}

The phytochemical analysis showed that in methanolic extracts along with constituents of aqueous extract alkaloids and triterpinoids were also present this justifies the presence of piperine in the formulation. The results of zone of inhibition study revealed that the test extracts possessed antibacterial and anti-fungal activity in a concentration 
dependent manner against the test organisms at concentrations of 100 and $200 \mu \mathrm{g} / \mathrm{ml}$ and are significant with the reference drugs. The activity could be attributed to the presences of phytoconstituents viz., steroids, tannins, saponins, triterpenoids, alkaloids and flavonoids.The present antibacterial and antifungal property of the formulation might be due to presence of piperine and the cumulative effect of the above mentioned constituents in the formulation.

\section{Compliance with ethical standards}

\section{Acknowledgments}

We are grateful to Rajiv Gandhi University Health Sciences Bengaluru for providing fund under Advanced Research Project Proposal.

\section{Disclosure of conflict of interest}

'The authors declare that there is no conflict of interest'.

\section{References}

[1] Ramawat KG and Merillon JM (Eds.). (2008). Bioactive Molecules and Medicinal Plants Published Springer-Verlag Berlin Heidelberg. In "The Indian Herbal Drugs Scenario in Global Perspectives", 328-29.

[2] CSIR. (2003). The Ayurvedic Pharmacopoiea of India, Part I, II Edition, Published by the Controller of Publication, New Delhi-1100012., 348-349.

[3] Maitreyi Zaveri1, Amit Khandhar, Samir Patel and Archita Patel. (2010). Chemistry and Pharmacology of Piper longum L, International Journal of Pharmaceutical Sciences Review and Research, 5, 1, 67-76.

[4] Zainab TKAldaly. (2010). Antimicrobial Activity of Piperine purified from piper nigrum, Journal of Basrah Researches (Sciences), 36(5).

[5] Gasem Mohammad and Abu-Taweel. (2018). Cardamom (Elettaria cardamomum) perinatal exposure effects on the development, behavior and biochemical parameters in mice offspring. Saudi Journal of Biological Sciences, $25,186-193$.

[6] Diego F. et al. (2018). Antibacterial and Antibiofilm Activities of Cinnamomum Sp. Essential Oil and Cinnamaldehyde: Antimicrobial Activities Scientific World Journal, Volume, 1-9.

[7] Harborne JB. (1998). Phytochemical Methods, A guide to modern techniques of plant analysis, 3rd Edn, Chapman and Hall, London, 235.

[8] Khandelwal KR. (2001). Practical Pharmacognosy Techniques and Experiments, 8th edn, Nirali Publication, Pune, 149-156.

[9] Srinivasa Reddy P, Kaiser Jamil, P. Madhusudhan, G. Anjani and B. Das. (2001). Antibacterial Activity of Isolates from Piper longum and Taxus baccata. Pharmaceutical Biology, 39, 3, 236-238.

[10] Nisha Sharma and Purshotam Kaushik. (2014). Medicinal, biological and pharmacological aspects of Plumbago zeylanica (Linn.). Journal of Pharmacognosy and Phytochemistry, 3(4), 117-120.

\section{How to cite this article}

Ekbote Maruthi T, Rajashekar VK, Shankarappa L and Bharathi DR. (2019). Phytochemical and antimicrobial screening of sitopaladi churna. GSC Advanced Research and Reviews, 1(2), 16-19. 